Research Article

\title{
Decision-Making for Fire Emergency of Urban Rail Transit Based on Prospect Theory
}

\author{
Yuning Wang $\mathbb{D}^{1},{ }^{1}$ Yingzi Liang $\mathbb{D}^{2},{ }^{2}$ Hui Sun $\mathbb{D}^{2},{ }^{2}$ and Yufei Yang $\mathbb{D}^{3}$ \\ ${ }^{1}$ School of Geographic and Environmental Sciences, Tianjin Normal University, Tianjin, China \\ ${ }^{2}$ College of Management and Economics, Tianjin University, Tianjin, China \\ ${ }^{3}$ School of Public Finance \& Economics, Shanxi University of Finance and Economics, Taiyuan, Shanxi, China \\ Correspondence should be addressed to Hui Sun; sunhui@tju.edu.cn
}

Received 31 July 2020; Revised 10 December 2020; Accepted 21 May 2021; Published 27 May 2021

Academic Editor: Kai Zhang

Copyright ( 2021 Yuning Wang et al. This is an open access article distributed under the Creative Commons Attribution License, which permits unrestricted use, distribution, and reproduction in any medium, provided the original work is properly cited.

Fire emergency response of urban rail transit is a complex multiattribute risk decision-making problem. In emergency response analysis, it is necessary to consider the psychological behaviors of decision-makers such as reference dependence, loss aversion, and judge distortion. Applying different emergency plans can intervene the development and evolution of urban rail emergency fire and may even result in different levels of casualties and property losses. For this situation, this paper proposes an emergency response decision-making method based on prospect theory. First, according to the prospect theory, this paper quantitatively describes the comprehensive psychological perception of decision-makers for casualties and property losses in different situations. Then, the psychological perception of decision-makers for the important levels of different situations is calculated. Third, according to the situation comprehensive values, situation weights, and the cost inputs of emergency plans, the comprehensive prospect values of each emergency plan are calculated, and the fire emergency plans can be ranked based on comprehensive prospect value. At last, the fire emergency disposal of Tianjin rail transportation line 3 is considered as the background in this paper. The feasibility and effectiveness of the purposed method is illustrated through the case study.

\section{Introduction}

With the economic and social development of China, especially the acceleration of urbanization process, the dramatic increase of urban population, the continuous improvement of motorization level, the increase of intensity and frequency of residents' travel, and the sustaining growth of traffic demand, the urban traffic functions are facing higher requirements and challenges [1]. At present, traffic congestion, traffic safety, air and noise pollution, and other problems in major cities such as Beijing, Shanghai, and Guangzhou have become increasingly serious. These problems have become the bottleneck that hinders the economic development of large cities. Although a series of measures have been taken, it is still unable to fundamentally solve the traffic congestion problem. Practice presents that giving priority to the development of public transportation and forming an integrated urban transportation system with rail transit as the backbone is the only way which must be passed to solve the traffic problems in major cities [2].

Comparing to other urban transportation vehicles, the subway owns the advantages of large passenger capacity, fast speed, less pollution, less energy consumption, and less land occupation. It has gradually become the preferred transportation mode for people's daily travel [3]. However, since the operation of the subway is below the horizon, the internal structure is relatively closed, and the numbers of entrances and exits are relatively small. Therefore, once an emergency occurs inside the subway, the rescue force and rescue equipment are extremely difficult to enter the underground space deeply, which is very likely to cause passengers casualties and major economic losses [4]. For example, in 1995, a fire occurred in the Azerbaijan subway caused by electrical failure, resulting in 558 deaths and 269 injuries; a man-made arson in Daegu, South Korea, caused a total of 198 deaths and 146 injuries in 2003. When an 
emergency occurs, the emergency managers or decisionmakers (DMs) often need to make a reasonable emergency response or choose an appropriate response action to reduce the consequent negative effect [5]. Urban rail transit fire emergency decision-making refers to a series of decisionmaking activities carried out to respond to and control the continuous development of fire emergency events in the early stage of an emergency. It is required to collect and handle relevant information of the emergency event, clarify problems and objectives, and formulate and select emergency action plans for implementation within limited time. At the same time, it is a dynamic process which needs to conduct continuous inspection for emergency situation and correct mistakes during the decision-making process, until the emergency event has been solved properly [6]. Objective factors affecting emergency decision-making include the suddenness of emergencies, the high uncertainty of evolution, complex and variable emergency decision-making environment, unconventional emergency decision-making procedures, urgent emergency decision-making timelines, high-risk decision-making effects, and so on. The subjective influencing factors are mainly reflected in the psychological behavior characteristics of decision-makers in the emergency decision-making environment. These influencing factors undoubtedly increase the difficulty of emergency decision-making [7]. Therefore, in the fire emergency decision-making environment, it is a difficult problem that how to eliminate the influence of subjective and objective factors of emergency decision-making and conduct the selection and adjustment of emergency plan based on the dynamic evolution of fire emergency situation in the research of rail transit fire emergency decision-making.

Currently, researches about decision-making methods of emergency response have attracted the attention of scholars. $\mathrm{Fu}$ proposed a decision-making method based on fuzzy approximation ideal point for the emergency plan selection of flood control dispatching [8]. Hämäläinen et al. proposed a decision-making method based on multiattribute utility theory for the emergency plan selection of nuclear accident [9]. Levy and Taji proposed a group analytic network process (GANP) decision-making method for the selection of flood disaster response plan considering attribute correlation [10]. Some existing research results show that the involution of emergency events is uncertain, and the implementation of one emergency plan may result in the occurrence of different emergency scenarios. Thus, the emergency response of emergency event is generally the multiattribute risk decision-making problem. The classical multiattribute decisionmaking method is established based on the "expected utility theory." But in the actual decision-making process, the irrational psychology of decision-makers and the randomness and ambiguity of their preferences will have a nonnegligible influence on the decision-making results [5]. Influenced by their own cognitive level and irrational psychological factors, in the face of uncertain multiattribute decision-making problems, decision-makers have personal expectations and prospects for a certain plan under a certain attribute. There is also rejoicing or regret and other thoughts during the decision-making process, and these will have an important impact on the decision-making results [11]. The existing studies have made important contributions to decision analysis in emergency response. These studies provided a variety of decision analysis methods for emergency response to support the decision-making of the decision support system. However, in the existing decision analysis methods for emergency response, the decision-makers' behavior is rarely considered. To this end, many experts and scholars have proposed many new theories, trying to describe the irrational psychology of people in the decision-making process, the most typical of which is the prospect theory (PT) proposed by Kahneman and Tversky [12]. This is because PT can describe the DMs' behavioral characteristics appropriately and give the calculation formulas on values and weights of potential outcomes. Since the formulas have features of clear logic and simple computation process, PT has been widely used to solve various decision-making problems considering DMs' behavior. Therefore, how to incorporate PT into decision analysis in emergency response deserves more attention [5]. Based on PT, this paper develops a decision analysis method to solve the risk decision-making problem in fire emergency response of urban rail transit, calculating the comprehensive psychological perception of decision-maker for casualties and property losses in different scenarios of the fire emergency event. Based on this, psychological perception of decision-maker for the important levels of occurrence of different scenarios can be calculated. At last, according to the scenario comprehensive value, scenario weight, and the cost inputs of emergency plan, the comprehensive prospect value of each emergency plan can be calculated; the rank of emergency plans can also be defined. The main contributions of this paper are as follows: (1) This paper establishes an emergency decision-making method based on the prospect theory and it is more operable for decision-makers. (2) The proposed method considers the psychological behavior of human beings. By applying the value function and the weight function in the foreground theory to replace the utility function and probability in the expected utility theory, respectively, the psychological behavioral characteristics can be presented in rail transit emergency fire responding risk decision-making. And it is more suitable for the decision-makers to analyze the whole process scenarios of fire emergency in urban rail transit.

The structure of the rest parts in this paper is as follows. Section 2 provides a literature review of the relevant research. Section 3 introduces the prospect theory. Section 4 analyzes the fire emergency plan of urban rail transit in Tianjin, China. Section 5 gives the conclusions.

\section{Literature Review}

2.1. Research on the Decision-Making of Emergency Event. Currently, the multiattribute group decision-making problem of emergency event response has attracted wide attention among scholars. Yu and Lai proposed an emergency response group decision-making method based on distance measure, which applies linear weighting to aggregate the information of decision-maker and reaches consensus, it provides a new idea for unconventional 
multiattribute emergency group decision-making problem [13]. Levy and Taji proposed a method based on group analysis network process using group network analysis method to solve risk plan and emergency management within incomplete information; group decision-making opinions are fully considered through this method [10]. For the unconventional emergency management of binary fuzzy language attribute values, Fu used the method which combines arithmetic weighted average and ordered weighted average operator to conduct group decisionmaking information aggregation [8]. Hämäläinen et al. proposed a multiattribute utility theory method to select the satisfactory response scheme, which aims to protect the personnel safety in nuclear emergency events [9]. Körte proposed a risk analysis method for emergency decisionmaking within variable and changing scenarios [7]. Geldermann et al. (2009) proposed an evaluation method based on multiattribute decision-making to select the best of many feasible solutions during the nuclear accident repair process [14]. To reduce the flood damage, Lim and Lee proposed a multiattribute decision analysis method to evaluate emergency plans [15]. Ergu et al. proposed a simple consistency checking process which makes the network analytic hierarchy process more suitable for solving emergency response decision-making problems [16]. Shim et al. proposed a decision-making support system to control flood emergencies [17]. Levy proposed a decision-making support system for flood disaster management, which involves multiattribute decision-making methods, remote sensing, geographic information systems, hydrological models, and real-time flood information systems [18]. Fogli et al. designed an emergency management decision-making support system and proposed an emergency management design plan based on the design model. The effectiveness of the design model has been evaluated by professional designers [19]. Mendonça et al. believed that effective emergency response has two key factors: the speed of response strategy and the knowledge quality of experts. They proposed a knowledge method applying computer technology and communication technology to improve emergency response capability [20]. Millar et al. proposed a mathematical programming model to help decision-makers choose an optimal plan for recovery strategies [21]. De Maio et al. proposed an emergency feature-based knowledge processing and resource discovery method based on fuzzy cognitive graphs [22]. Luna and Pennock reviewed the current state of the application of social media in emergency management and the benefits and possible risk challenges in emergency decision-making process [23].

Most of the existing emergency decision-making research is based on the expected utility theory, assuming the decision-maker is an "economic man." However, in the actual emergency decision-making process, decision-makers present limited rationality because of their own cognition, psychology, experience, and other subjective factors. Moreover, emergency decision-making is a type of group decision-making. The subjective factors of each individual are different, and decision-making results are also different. These make the aggregation decision-makers' information more valuable and meaningful. Therefore, it is worthy of further study that how to take into account the psychological behavioral factors of different decision-makers in the emergency decision-making process. And the DMs' behavioral characteristics such as reference dependence, loss aversion, and judgmental distortion are considered in risk decision analysis because the DMs are often bounded rational in emergency response. The consideration is neglected in the existing studies.

2.2. Research on the Application of Prospect Theory. After a lot of practical researches, Kahneman and Tversky proposed the prospect theory in 1979 [12]. Subsequently, prospect theory was widely applied. Young et al. studied the impact of time pressure on decision-making behaviors based on the prospect theory framework. Through the data modeling to establish the psychological mechanism of decision-making behaviors, the results present that, under time pressure, actor has the tendency to increase the risk to seek profit. These provide theoretical support for the original research [24]. In the study of cumulative prospect theory, Goda and Hong attempted to use it to reveal implicit seismic design preference of bounded rational decision-makers. They researched the implicit seismic design preference by applying static penetration method, seismic risk assessment, and life cycle cost analysis and evaluated the influence of applied value number and model parameters of weighting function on design preferences through numerical examples [25]. Lewandowski researched the complementary symmetry in the cumulative theory by applying random reference. The result shows that if the utility function of profits and losses is strictly increasing and continuous, the cumulative prospect theory has the complementary symmetry of the random reference. More restrictions are imposed in prospect theory, including preference homogeneity, reflection, and loss aversion [26]. Klein and Deissenroth researched that the residents were suitable to invest solar photovoltaic power generation by applying prospect theory. As a case study, the report model presents that the loss aversion of prospect theory explains that the investment of people on photovoltaic system not only depends on profitability, but also depends on changes of profitability relative to the current situation [27]. Vipin and Amit researched the decision bias problem in the newsboy model applying prospect theory. Considering prospect theory model and the random subjective reference point, the reference point is the return based on the corresponding demand extreme value. Prospect theory model not only describes pull center effect and the asymmetrical ordering, but also research the results of nonlinear order behavior in extreme profitability and behavior inspect in the newsboy experiment [28]. KairiesSchwarz et al. studied health insurance choices and risk appetite based on prospect theory, that is, how consumers will select insurance contracts based on individual risk preferences. They elicited risk appetite of experimental subject by using sequential designed laboratory experiments. Considering the cumulative prospect theory and the expected utility theory, they found that the majority of 
experimental subjects conform with the cumulative prospect theory [29].

The emergency response decision-making theory and method have been improved and developed by the existing researches, which focus on the emergency response decisionmaking method within the prediction information under uncertain scenario. The emergency events own the uncertainty and unpredictability. At the same time, decision-makers must respond under tremendous pressure, and the effectiveness of each response plan is uncertain. By building scientific and reasonable guidelines, applying interval numbers to reasonably express the preference information of decision-makers and assemble the information, decision-makers evaluate and optimize the designed several optional plans, and implement emergency response measure quickly. Therefore, how to effectively express and assemble the opinions of decisionmakers is an issue that must be considered when researching emergency response group decision-making. In addition, based on the prospect theory, this paper obtains the comprehensive prospect value of each plan and then to rank the plan.

\section{Methodology}

3.1. Basic Concepts and Definitions of Prospect Theory. Prospect theory was proposed by Kahneman and Tversky [12]. It is a descriptive theory for human decision behavior under uncertainty, and the rank dependent expected utility model [5]. Prospect theory is a decision model of descriptive paradigm. It has three characteristics: most people are riskaverse when facing acquisition; most people are risk-preferred when facing losses; and people are more sensitive to loss than gain. Therefore, people are often cautious when faced with gains and are not willing to take risks, but people will be very unwilling and easy to take risks when faced with loss. People usually own different sensitivity to loss and gain. The pain at loss is much greater than the joy at gain. In the prospect theory model, the decision-making process is divided into editing phase and evaluation phase. The editing phase refers to the rough analysis of the set prospects, and the quantification presents the phonetic scale of prospect. The evaluation phase refers to the value of the evaluation prospects, making the highest as the most superior. The role of the editor is to use appropriate forms to express attribute values and then simplify evaluation process. This is mainly achieved by converting prospect values and probabilities. The editing phase mainly includes coding, integration, and separation. Among them, past studies have shown that people perceive the profits or losses, not the actual value of wealth. Thus, it is necessary to obtain a judgment that whether the current assets belong to the profits or losses relative to the reference point by coding. In this case, the selection of the reference point and the result coding which changes with the fluctuation of reference point are influenced by the expectation of decision-making subject and the presentation method of prospect. Integration means that sometimes the comprehensive prospect value gained by combining probability weight function of same result. Riskfree parts are separated during the editing process to simplify the analysis process. Besides, the particularly important form includes the abandonment of extremely impossible outcomes, which means eliminating nondominant ones and omitting the need for further evaluation. Evaluation process is to conduct corresponding calculation according to the formula on the basis of the editing process and then make the final decision.

According to prospect theory, the edited total value $V$ of one event in uncertain situation is determined by two realvalued function: value function $v(x)$ and decision-making weight function $\omega(p)$. $\omega(p)$ is relevant with the occurrence probability of each event; $v(x)$ reflects the subject value of the result, which is the profits or losses [26-28].

3.2. Description of the Model. Assume $A=\left\{A_{1}, A_{2}, \ldots, A_{m}\right\}$ as the set of $m$ alternative emergency plans, where $A_{i}$ presents the $i$ th alternative emergency plan, $i=1,2, \ldots, m$. $C=\left\{c_{1}, c_{2}, \ldots, c_{m}\right\}$ presents the cost input vector of the plan; $c_{i}$ presents the total cost inputs of plan $A_{i} . S=\left\{S_{1}, S_{2}, \ldots, S_{n}\right\}$ presents the set of $n$ scenarios that emergency event may occur; $S_{j}$ presents the $j$ th possible scenario, $j=1,2, \ldots, n$. $L_{1}=\left(\widetilde{l}_{11}, \widetilde{l}_{12}, \ldots, \widetilde{l}_{1 n}\right)$ presents the casualty vector; $\widetilde{l}_{1 j}$ presents the number of casualties caused by the occurrence of scenario $S_{j}$. As the occurrence of emergency event situation generally owns uncertainty, the number of casualties $\widetilde{l}_{1 j}$ also owns uncertainty. This paper assumes $\widetilde{l}_{1 j}$ as interval number information form, $\widetilde{l}_{1 j}=\left[l_{1 j}^{L}, l_{1 j}^{U}\right], l_{1 j}^{U} \geq l_{1 j}^{L} \geq 0, j=1,2, \ldots, n$. $L_{2}=\left(\tilde{l}_{21}, \tilde{l}_{22}, \ldots, \tilde{l}_{2 n}\right)$ presents the property losses, $\tilde{l}_{2 j}$ presents the property losses caused by the occurrence of scenario $S_{j}$. Similarly, this paper assumes $\tilde{l}_{2 j}$ as interval number information form, $\widetilde{l}_{2 j}=\left[l_{2 j}^{L}, l_{2 j}^{U}\right], l_{2 j}^{U} \geq l_{2 j}^{L} \geq 0, j=1,2, \ldots, n$. $P=\left[p_{i j}\right]_{m \times n}$ presents scenario probability matrix; $p_{i j}$ presents the occurrence probability of scenario $S_{j}$ by applying plan $A_{i}, 0 \leq p_{i j} \leq 1$. Also, for $\forall i \in\{1,2, \ldots, m\}$, $\sum_{j=1}^{n} p_{i j}=1 . c^{R}, l_{1}^{R}, l_{2}^{R}$ present the psychological expectations of decision-maker for plan cost inputs, the number of casualties caused by emergency event, and the property losses. In emergency decision-making problem, based on cognition of emergency event, knowledge, and pass experience, decision-maker generally will generate some psychological expectation for response costs, casualties, and property losses of the emergency event. If the actual cost inputs, casualties, and property losses are less than the corresponding expectation, psychological perception of decisionmaker is profit. On the contrary, psychological perception is loss. $\omega=\left(\omega_{1}, \omega_{2}\right)$ presents the weight vectors of casualties and property losses, $\omega_{1}$ presents the important level of casualties, and $\omega_{2}$ presents the important level of property losses, satisfying $\omega_{1}+\omega_{2}=1,0 \leq \omega_{1}, \omega_{2} \leq 1$.

The calculation of prospect theory can be divided into three steps. First, decision-maker is required to select the proper reference point and compare the decision-making information and reference point, to establish the "prospect" of the decision-making problem, which is the profit or loss of each decision-making plan comparing to reference point. 
Then, the scenario weight can be calculated according to the psychological behavior characteristics of decision-maker. Third, the editing evaluation can be conducted to the gained prospect and then the decision-making results can be obtained $[12,30,31]$.

Step 1. Calculate the prospect values of plans.

For the reference dependence psychological behavior characteristic of decision-maker, which means that decisionmaker regard the result as profit or loss comparing to reference point. Calculate the profit and loss value $\left(\widetilde{e}_{1 j}\right)$ of the number of casualties $\widetilde{l}_{1 j}$ comparing to reference point $l_{1}^{R}$ in scenario $S_{j}$, which is

$$
\tilde{e}_{1 j}=\widetilde{l}_{1 j}-l_{1}^{R}=\left[l_{1 j}^{L}-l_{1}^{R}, l_{1 j}^{U}-l_{1}^{R}\right]=\left[e_{1 j}^{L}, e_{1 j}^{U}\right] .
$$

According to formula (1), $\tilde{e}_{1 j}=\left[e_{1 j}^{L}, e_{1 j}^{U}\right]$ is an interval number. If $e_{1 j}^{L}>0$, the number of casualties caused by scenario $S_{j}$ is larger than the reference point $l_{1}^{R}$, then the psychological perception of decision-maker is loss. If $e_{1 j}^{U}<0$, the number of casualties is smaller than the reference point $l_{1}^{R}$, then the psychological perception of decision-maker is profit. If $e_{1 j}^{L} \leq 0 \leq e_{1 j}^{U}$, the number of casualties may be larger or smaller than the reference point, then the psychological perception of decision-maker can be loss or profit.

To calculate the value of casualties in scenario $S_{j}$, assume $e_{1 j}$ as the random variable in interval $\left[e_{1 j}^{L}, e_{1 j}^{U}\right], f_{1 j}\left(e_{1 j}\right)$ is the probability density function of $e_{1 j}$. Calculate the value of casualties in scenario $S_{j}$ according to the following formula:

$$
v_{1 j}=\left\{\begin{array}{l}
\int_{e_{1 j}^{L}}^{e_{1 j}^{U}} v_{1}^{-}\left(e_{1 j}\right) f_{1 j}\left(e_{1 j}\right) \mathrm{d} e_{1 j}, \quad e_{1 j}^{L}>0, \\
\int_{e_{1 j}^{L}}^{0} v_{1}^{+}\left(e_{1 j}\right) f_{1 j}\left(e_{1 j}\right) \mathrm{d} e_{1 j}+\int_{0}^{e_{1 j}^{U}} v_{1}^{-}\left(e_{1 j}\right) f_{1 j}\left(e_{1 j}\right) \mathrm{d} e_{1 j}, \quad e_{1 j}^{L} \leq 0 \leq e_{1 j}^{U}, \\
\int_{e_{1 j}^{U}}^{e_{1 j}^{L}} v_{1}^{+}\left(e_{1 j}\right) f_{1 j}\left(e_{1 j}\right) \mathrm{d} e_{1 j}, \quad e_{1 j}^{U}<0 .
\end{array}\right.
$$

Besides, when $e_{1 j} \leq 0, v_{1}^{-}\left(e_{1 j}\right)$ presents the negative value of the psychological perception of decision-maker; when $e_{1 j} \geq 0, v_{1}^{+}\left(e_{1 j}\right)$ presents the positive value of the psychological perception of decision-maker. According to the thinking of prospect theory, the calculation formulas for $v_{1}^{+}\left(e_{1 j}\right)$ and $v_{1}^{-}\left(e_{1 j}\right)$ are

$$
\begin{aligned}
& v_{1}^{+}\left(e_{1 j}\right)=\left(-e_{1 j}\right)^{\alpha_{1}}, \quad e_{1 j} \leq 0, \\
& v_{1}^{-}\left(e_{1 j}\right)=-\lambda_{1}\left(e_{1 j}\right)^{\beta_{1}}, \quad e_{1 j} \geq 0 .
\end{aligned}
$$

Besides, parameters $\alpha_{1}$ and $\beta_{1}\left(0 \leq \alpha_{1}, \beta_{1} \leq 1\right)$ separately present the concave and convex degrees of the profit and loss value function for casualties, the larger $\alpha_{1}$ and $\beta_{1}$, the more significant concave and convex degrees of the profit and loss value function for casualties. These reflect the psychological behavioral characteristic of decision-maker that the sensibility for casualties reduces continuously. Parameter $\lambda_{1}>1$ presents the decision-maker owns the psychological behavioral characteristic that the decision-maker is more sensitive on loss of the casualties rather than profit. The larger $\lambda_{1}$ presents that the loss aversion degree of decisionmaker for casualties is larger.

Similarly, calculate the value of property loss $\left(v_{2 j}\right)$ in scenario $S_{j}$ :

$$
v_{2 j}=\left\{\begin{array}{l}
\int_{e_{2 j}^{L}}^{e_{2 j}^{U}} v_{2}^{-}\left(e_{2 j}\right) f_{2 j}\left(e_{2 j}\right) \mathrm{d} e_{2 j}, \quad e_{2 j}^{L}>0, \\
\int_{e_{2 j}^{L}}^{0} v_{2}^{+}\left(e_{2 j}\right) f_{2 j}\left(e_{2 j}\right) \mathrm{d} e_{2 j}+\int_{0}^{e_{2 j}^{U}} v_{2}^{-}\left(e_{2 j}\right) f_{2 j}\left(e_{2 j}\right) \mathrm{d} e_{2 j}, \quad e_{2 j}^{L} \leq 0 \leq e_{2 j}^{U}, \\
\int_{e_{2 j}^{U}}^{e_{2 j}^{L}} v_{2}^{+}\left(e_{2 j}\right) f_{2 j}\left(e_{2 j}\right) \mathrm{d} e_{2 j}, \quad e_{2 j}^{U}<0 .
\end{array}\right.
$$

Besides,

$$
\begin{gathered}
\tilde{e}_{2 j}=\tilde{l}_{2 j}-l_{2}^{R}=\left[l_{2 j}^{L}-l_{2}^{R}, l_{2 j}^{U}-l_{2}^{R}\right]=\left[e_{2 j}^{L}, e_{2 j}^{U}\right], \\
v_{2}^{+}\left(e_{2 j}\right)=\left(-e_{2 j}\right)^{\alpha_{2}}, \quad e_{2 j} \leq 0,
\end{gathered}
$$

$$
v_{2}^{-}\left(e_{2 j}\right)=-\lambda_{2}\left(e_{2 j}\right)^{\beta_{2}}, \quad e_{2 j} \geq 0 .
$$

In formulas (5)-(8), $f_{2 j}\left(e_{2 j}\right)$ is the probability density function of property loss $e_{1 j}$. Parameters $\alpha_{2}$ and $\beta_{2}$ $\left(0 \leq \alpha_{2}, \beta_{2} \leq 1\right)$ separately present the concave and convex degrees of the profit and loss value function for property 
losses; the larger $\alpha_{2}$ and $\beta_{2}$, the more significant concave and convex degrees of the profit and loss value function for property losses. These reflect the psychological behavioral characteristic of decision-maker that the sensibility for property losses reduces continuously. Parameter $\lambda_{2}>1$ presents the decision-maker owns the psychological behavioral characteristic that the decision-maker is more sensitive on property losses rather than profits. The larger $\lambda_{2}$ presents that the loss aversion degree of decision-maker for property loss is larger.

Further, in order to eliminate the influence of different dimensions on the calculation results, standardize the value of casualties $v_{1 j}$ and the value of property losses $v_{2 j}$ in scenario $S_{j}$ as $\bar{v}_{1 j}$ and $\bar{v}_{2 j}$. The standardized formula is

$$
\bar{v}_{k j}=\frac{v_{k j}}{\left|v_{k}\right|^{\max }} \text {. }
$$

This includes $\left|v_{k}\right|^{\max }=\max \left\{\left|v_{k 1}\right|,\left|v_{k 2}\right|, \ldots,\left|v_{k n}\right|\right\}$, $k=1,2$. Based on this, according to the casualties and property losses, the comprehensive value $\left(v_{j}\right)$ of scenario $S_{j}$ can be calculated as

$$
v_{j}=\omega_{1} \bar{v}_{1 j}+\omega_{2} \bar{v}_{2 j} .
$$

\section{Step 2. Calculate scenario weight.}

For the judgment distortion psychological behavioral characteristic of decision-maker, this paper provides the calculation method of scenario weight according to the thinking of prospect theory. First, $v_{1}, v_{2}, \ldots, v_{n}$ can be ranked from biggest to smallest, gaining $v_{(1)} \geq \cdots \geq$ $v_{(h)} \geq 0 \geq v_{(h+1)} \geq \cdots \geq v_{(n)} . v_{(g)}$ presents the $g$ th scenario comprehensive value between $v_{1}, v_{2}, \ldots, v_{n}$. If $g \leq h$, then $v_{(g)} \geq 0$; if $g \geq h+1$, then $v_{(g)} \leq 0, g \in\{1,2, \ldots, n\}$. Correspondingly, assume the emergency event scenario of $v_{(g)}$ as $S_{(g)}, S_{(g)} \in S$. Take $p_{i(g)}$ that presents the occurrence probability of scenario $S_{(g)}$ by applying plan $A_{i}$. If $S_{(g)}=S_{j}$, then $p_{i(g)}=p_{i j}$. Then, according to prospect theory, the important level or weight of the occurrence of scenario $S_{(g)}$ perceived by decision-maker applying plan $A_{i}$ can be presented as

$$
\pi_{i(g)}=\left\{\begin{array}{l}
w^{+}\left(\sum_{j=1}^{g} p_{i(j)}\right)-w^{+}\left(\sum_{j=1}^{g-1} p_{i(j)}\right), \quad g=1,2, \ldots, h, \\
w^{-}\left(\sum_{j=g}^{n} p_{i(j)}\right)-w^{-}\left(\sum_{j=g+1}^{n} p_{i(j)}\right), \quad g=h+1, h+2, \ldots, n .
\end{array}\right.
$$

This includes functions $\omega^{+}(\cdot)$ and $\omega^{-}(\cdot)$ being the nonlinear weight functions for profits and losses, respectively. The formulas are

$$
\begin{aligned}
& \omega^{+}(p)=\frac{p^{\chi}}{\left[p^{\chi}+(1-p)^{\chi}\right]^{1 / \chi}}, \\
& \omega^{-}(p)=\frac{p^{\delta}}{\left[p^{\delta}+(1-p)^{\delta}\right]^{1 / \delta}} .
\end{aligned}
$$

According to references $[12,30,31], \chi=0.61$ and $\delta=0.69$.

Step 3. Calculate the comprehensive prospect values of plans.

According to the scenario values $v_{(1)}, v_{(2)}, \ldots, v_{(n)}$, scenario weights $\pi_{i(1)}, \pi_{i(2)}, \ldots, \pi_{i(n)}$, plan cost vector $C=\left\{c_{1}, c_{2}, \ldots, c_{m}\right\}$, and the psychological expectation $c^{R}$ of decision-maker for cost, the comprehensive prospect values of plans can be calculated.

First, according to $v_{(1)}, v_{(2)}, \ldots, v_{(n)}$ and $\pi_{i(1)}, \pi_{i(2)}, \ldots, \pi_{i(n)}$, the expected prospect value $\mathrm{EV}_{i}$ of plan $A_{i}$ can be calculated as

$$
\mathrm{EV}_{i}=\sum_{g=1}^{n} v_{(g)} \pi_{i(g)}
$$

Then, considering the cost inputs of the plan, calculate the profit and loss value of cost $c_{i}$ of plan $A_{i}$ comparing to reference point $c^{R}$ :

$$
d_{i}=c_{i}-c^{R} .
$$

According to formula (15), if $d_{i}>0$, then the psychological perception of decision-maker for cost inputs of plan $A_{i}$ is loss. If $d_{i}<0$, then the psychological perception of decision-maker for cost inputs of plan $A_{i}$ is profit. Therefore, the cost value of plan $A_{i}$ is

$$
v_{i}^{C}= \begin{cases}-\left(d_{i}\right)^{\alpha_{3}}, & d_{i} \leq 0, \\ -\lambda_{3}\left(d_{i}\right)^{\beta_{3}}, & d_{i}>0 .\end{cases}
$$

Besides, parameters $\alpha_{3}$ and $\beta_{3}\left(0 \leq \alpha_{3}, \beta_{3} \leq 1\right)$ separately present the concave and convex degrees of the profit and loss value function for cost inputs; the larger $\alpha_{3}$ and $\beta_{3}$, the more significant concave and convex degrees of the profit and loss value function for cost inputs. This reflects the psychological behavioral characteristic of decision-maker that the sensibility for cost inputs reduces continuously. Parameter $\lambda_{3}>1$ presents the decision-maker owns the psychological behavioral characteristic that the decision-maker is more sensitive on loss of the cost inputs rather than profit. The larger $\lambda_{3}$ presents that the loss aversion degree of decisionmaker for cost inputs is larger.

Moreover, in order to eliminate the influence of different dimensions on the calculation results, the expected prospect value $\mathrm{EV}_{i}$ and cost prospect value $v_{i}^{C}$ of plan $A_{i}$ can be standardized as $\overline{\mathrm{EV}}_{i}$ and $\bar{v}_{i}^{C}$. The calculation formulas are

$$
\begin{gathered}
\overline{\mathrm{EV}}_{i}=\frac{\mathrm{EV}_{i}}{|\mathrm{EV}|^{\max }}, \\
\bar{v}_{i}^{C}=\frac{v_{i}^{C}}{\left|v^{C}\right|^{\text {max }} .}
\end{gathered}
$$

Besides, $|\mathrm{EV}|^{\max }=\max \left\{\left|\mathrm{EV}_{1}\right|,\left|\mathrm{EV}_{2}\right|, \ldots,\left|\mathrm{EV}_{m}\right|\right\}$ and $\left|v^{C}\right|^{\max }=\max \left\{\left|v_{1}^{C}\right|,\left|v_{2}^{C}\right|, \ldots,\left|v_{m}^{C}\right|\right\}$. According to formula (18), $0 \leq\left|\overline{\mathrm{EV}}_{i}\right|,\left|\bar{v}_{i}^{\mathrm{C}}\right| \leq 1$. 
Based on these, the comprehensive prospect value of plan $A_{i}$ can be calculated as

$$
\mathrm{OV}_{i}=\gamma_{1} \overline{\mathrm{EV}}_{i}+\gamma_{2} \bar{v}_{i}^{C}
$$

In addition, $\gamma_{1}$ and $\gamma_{2}$ separately present the important levels of the uncertain profit or loss and certain cost inputs; $\gamma_{1}$ and $\gamma_{2}$ are generally provided by the decision-maker and satisfy $0 \leq \gamma_{1}, \gamma_{2} \leq 1, \gamma_{1}+\gamma_{2}=1$. Obviously, the larger $\mathrm{OV}_{i}$, the better plan $A_{i}$.

\section{Case Study}

4.1. The Selection of Research Area. Tianjin is one of the four municipalities in China; it is also the important transportation junction and the biggest harbor city in North China. There are 16 districts in Tianjin, covering 11,916.85 square kilometers area; territory circumference is $1,290.814$ kilometers including the coastline for 153.334 kilometers and lithosphere line for 1,137.48 kilometers. The areas under administration can be divided into central city, Binhai new district, and suburbs. Central city area is the center of politics, culture, education, economy, and business for Tianjin. Binhai new district is the deputy provincial district in the east of Tianjin. There are 5 national development zones and 21 towns under the administration of Binhai new district. Binhai new district is the first free trade pilot zone, national comprehensive supporting reform pilot zone, and national independent innovation demonstration zone in North China.

Tianjin is the second city in China which owns subways after Beijing. At the initial stage of the operation, the network density of rail transit is low, and rail transit is not attractive to the public. With the new metro continuously putting into operation, the generated rail transit network has effectively facilitated the convenient travel of citizens. Until the end of 2019, there are 6 metro lines under operation in Tianjin: lines 1,2, and 3 are three radial backbone routes, Jinbin line 9 which connects the central city and Binhai new district, and filling lines 5 and 6 (Figure 1). The total operation length is 215 kilometers with 154 metro line stations, covering the 10 districts in Tianjin.

\subsection{Fire Emergency Decision-Making for Tianjin South Station} in Tianjin Metro Line 3. In this section, an example will be given based on the background of emergency decisionmaking from rail transportation fire to illustrate the validity of the proposed method. In 27 June 2019, there was a fire near Tianjin South Station in Tianjin Metro Line 3. To ensure the safety of passengers, Tianjin Rail Group prepared to select one of three fire emergency plans, which includes the following:

$A_{1}$ : using the fire-fighting facilities (dry powder fire extinguishers, indoor fire hydrants) equipped with subway stations to extinguish the fire. The cost of the plan $\left(c_{1}\right)$ is 200,000 US dollars.

$A_{2}$ : on the basis of using the fire-fighting facilities equipped with the subway station, open the subway

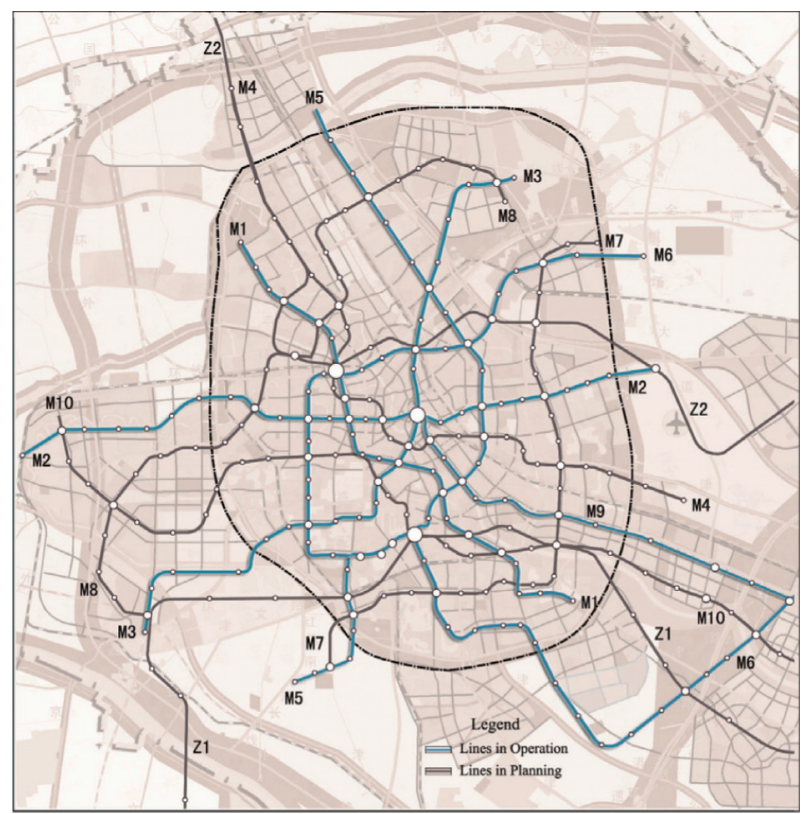

FIGURE 1: The urban rail transit line planning network of Tianjin in 2020.

automatic sprinkler system to outfire. The cost of the plan $\left(c_{2}\right)$ is 500,000 US dollars.

$A_{3}$ : on the basis of using the fire-fighting facilities equipped with the subway station and automatic sprinklers to outfire, the fire brigade is involved in the fire fighting. The cost of the plan $\left(c_{3}\right)$ is 800,000 US dollars.

By consulting disaster prevention experts, three typical scenarios for fire spread were identified:

$S_{1}$ : smoke from floor and platform level of the subway station. If this scenario occurs, the number of injured will be around 10-20; the expected economic loss is 1-1.5 million US dollars.

$S_{2}$ : a small area of open flame and heavy smoke appeared on floor and platform level of the subway station, causing power interruption. If this scenario occurs, the number of injuries will be $21-40$, and the expected economic loss is $2-3.5$ million US dollars.

$S_{3}$ : a large range of open flames and heavy smoke appeared on floor and platform level of the subway station, causing power interruption. If this scenario occurs, the number of injuries will be $41-70$, and the expected economic loss is $5-8$ million US dollars.

Assuming the reference point given by decision-maker as $c^{R}=60, l_{1}^{R}=30$, and $l_{2}^{R}=400$, the weight vectors of casualty and economic loss are $\omega=(0.8,0.2)$. According to the analysis of historical data and the experience of the disaster prevention experts, the occurrence probability of each scenario by applying different plans is shown in Table 1.

Then, the purposed method is applied for fire emergency decision-making for Tianjin South Station in Tianjin Metro Line 3. The calculation process is presented as follows. 
TABLE 1: Occurrence probability of each scenario by applying different plans.

\begin{tabular}{cccc}
\hline$p_{i j}$ & $S_{1}$ & $S_{2}$ & $S_{3}$ \\
\hline$A_{1}$ & 0.6 & 0.2 & 0.2 \\
$A_{2}$ & 0.7 & 0.2 & 0.1 \\
$A_{3}$ & 0.8 & 0.15 & 0.05 \\
\hline
\end{tabular}

4.2.1. Calculating the Prospect Value of Each Plan. According to formulas (1) and (6), the profit or loss of results can be calculated comparing to reference point, which are presented in Table 2.

According to formulas (2)-(5), $e_{k j}$ follows uniform distribution; then $f\left(e_{k j}\right)=\left(1 / e_{k j}^{U}-e_{k j}^{L}\right)$. According to $[12,30,31]$, taking $\alpha_{k}=0.89, \beta_{k}=0.92$, and $\lambda_{k}=2.25$, the value $v_{k j}$ of casualty and profit loss presented can be calculated as Table 3.

According to formula (9), standardizing the value of casualty and profit loss, then get $\bar{v}_{k j}$ as presented in Table 4 .

According to formula (10), calculate the comprehensive values of scenarios $S_{1}, S_{2}$, and $S_{3}$, which are $v_{1}=0.284$, $v_{2}=-0.0773$, and $v_{3}=-1$.

4.2.2. Calculating Scenario Weight. According to formulas (11)-(13), calculate the scenario weight $\pi_{i(g)}$ by applying different plans, $i=1,2,3, g=1,2,3$; get the scenario weight presented in Table 5.

4.2.3. Calculating the Comprehensive Prospect Value of Different Plans. According to formulas (14)-(16), calculate the expected prospect value $\mathrm{EV}_{i}$ and cost value $v_{i}^{C}$ of each plan; based on these, according to formulas (17)-(19), taking $\gamma_{1}=0.8$ and $\gamma_{2}=0.2$, calculate the comprehensive prospect value $\mathrm{OV}_{i}$. The corresponding calculation results are presented in Table 6. From Table 6, $\mathrm{OV}_{3}>0$, which presents that the input costs, casualties, and profit losses of plan $A_{3}$ perceiving by the decision-maker are better than the psychological expectation of decision-maker. On the contrary, $\mathrm{OV}_{1}<\mathrm{OV}_{2}<0$, which presents that the input costs, casualties, and profit losses of plan $A_{1}$ and $A_{2}$ perceiving by the decision-maker are worse than the psychological expectation of decision-maker, and plan $A_{2}$ is better than plan $A_{1}$. Therefore, the rank of plans is determined as $A_{3}>A_{2}>A_{1}$.

4.3. Comparative Analysis. In this part, we proposed two different decision-making methods and compared them with the prospect theory to prove the validity and feasibility of the proposed model. The first method is analytic hierarchy process (AHP), and the second method is technique for order preference by similarity to an ideal solution (TOPSIS) [32]. Thus, we could compare the results from different methods. The detailed calculation processes and parameter values of AHP and TOPSIS can be searched by [33-35]. Table 7 summarizes the ranking information for all alternatives by using these three decision-making methods.

Table 7 shows that the optimal alternative determined by the proposed method is significantly different from the
TABLE 2: $\widetilde{e}_{k j}$ value in different scenarios.

\begin{tabular}{cccc}
\hline & $S_{1}$ & $S_{2}$ & $S_{3}$ \\
\hline$\tilde{e}_{1 j}$ & {$[-20,-10]$} & {$[-9,10]$} & {$[11,40]$} \\
$\tilde{e}_{2 j}$ & {$[-300,-250]$} & {$[-200,-100]$} & {$[100,400]$} \\
\hline
\end{tabular}

TABLE 3: $v_{k j}$ value in different scenarios.

\begin{tabular}{cccc}
\hline & $S_{1}$ & $S_{2}$ & $S_{3}$ \\
\hline$v_{1 j}$ & 11.1164 & -6.9027 & -44.0948 \\
$v_{2 j}$ & 148.2328 & 86.2751 & -359.98 \\
\hline
\end{tabular}

TABLE 4: $\bar{v}_{k j}$ value in different scenarios.

\begin{tabular}{lccc}
\hline & $S_{1}$ & $S_{2}$ & $S_{3}$ \\
\hline $\bar{v}_{1 j}$ & 0.2521 & -0.1565 & -1 \\
$\bar{v}_{2 j}$ & 0.4117 & 0.2397 & -1 \\
\hline
\end{tabular}

TABLE 5: The computing result of $\pi_{i(g)}$.

\begin{tabular}{lccc}
\hline$\pi_{i(g)}$ & $S_{1}$ & $S_{2}$ & $S_{3}$ \\
\hline$A_{1}$ & 0.4769 & 0.1346 & 0.257 \\
$A_{2}$ & 0.5338 & 0.1574 & 0.1701 \\
$A_{3}$ & 0.6074 & 0.1456 & 0.1114 \\
\hline
\end{tabular}

TABLE 6: The computing result of $\mathrm{EV}_{i}, v_{i}^{C}$, and $\mathrm{OV}_{i}$.

\begin{tabular}{cccc}
\hline & $\mathrm{EV}_{i}$ & $v_{i}^{C}$ & $\mathrm{OV}_{i}$ \\
\hline$A_{1}$ & -0.1328 & 20.6366 & -0.6834 \\
$A_{2}$ & -0.0307 & 7.7625 & -0.141 \\
$A_{3}$ & 0.0498 & -35.4103 & 0.1002 \\
\hline
\end{tabular}

alternative obtained by AHP and TOPSIS. The reasons are as follows: (1) Compared with AHP and TOPSIS, prospect theory considers the expected utility of the plan and the decision-maker's psychological behavior. Therefore, decision-makers will compare the expected utility in the emergency response process. It overcomes the shortages occurring in the existing methods. (2) This method takes into account the uncertain scenario, by building scientific and reasonable guidelines, applying interval numbers to reasonably express the preference information of decisionmakers and assemble the information; decision-makers evaluate and optimize the designed several optional plans and implement emergency response measure quickly. In addition, the decision-making method based on AHP and TOPSIS does not consider the psychological behavior of the decision-maker and lacks the evaluation of the results of emergencies, thus affecting the accuracy of the evaluation. Therefore, this method involves human mental behavior. Compared with the completely rational assumption of decision-makers, the proposed method can deal with decisionmaking problems more reasonably and is more suitable for decision-makers to analyze the whole process scenarios of urban rail transit fire disasters. 
TABLE 7: Ranking results by using three different decision-making methods.

\begin{tabular}{lcccccc}
\hline \multirow{2}{*}{ Alternatives } & \multicolumn{2}{c}{ Prospect theory } & \multicolumn{2}{c}{ AHP } & \multicolumn{2}{c}{ TOPSIS } \\
& Comprehensive value & Ranking order & Comprehensive value & Ranking order & Comprehensive value & Ranking order \\
\hline$A_{1}$ & -0.6834 & 3 & 0.303 & 2 & 0.646 & 3 \\
$A_{2}$ & -0.141 & 2 & 0.584 & 1 & 0.822 & 1 \\
$A_{3}$ & 0.1002 & 1 & 0.113 & 3 & 0.667 & 2 \\
\hline
\end{tabular}

\section{Conclusion}

This paper proposes a risk decision-making method that considers the decision-maker's behavior in fire emergency response. On the basis of $\mathrm{PT}$, the negative effect value of each response result is added to the probability weight of each state, and the expected value of each response action is calculated. Then, the expected value and cost of each response action are added to obtain the total expected value of each response action. Further, the ordering of the response actions is determined based on the obtained overall prospect value. An application example is given to illustrate the application of the method. The contributions of this research are as follows.

The behavioral characteristics of decision-makers such as reference dependence, loss aversion, and judgment distortion are considered in risk decision analysis because decision-makers have often limited rationality in emergency response. It was ignored in previous studies. This paper provides a new solution for emergency response analysis considering decision-makers' behavior. It overcomes the deficiencies of existing methods. PT is used in the decision analysis. By applying the value function and the weight function in the foreground theory to replace the utility function and probability in the expected utility theory, respectively, the reference dependence, loss aversion and probability judgment distortion, and some other psychological behavioral characteristics of decision-makers can be presented in rail transit emergency fire responding risk decision-making. Therefore, the decision analysis results are more in line with the subjective perception of decisionmaker and are more easily accepted by decision-makers.

In the future research, four directions are identified as follows. First, the method can be extended to the emergency response problem of uncertain criteria values, such as random variables. Second, the uncertain reference point in decision analysis can be retrieved in uncertain database with measure-based belief function attribute values under intuitionistic fuzzy set. Linguistic interval-valued Pythagorean fuzzy sets and their application to multiple attribute group decision-making process. Third, due to the characteristics of risk decision-making, the decision-making process is mainly dependent on the experience of decisionmakers. For example, the determination on the $\chi, \delta$ in this article needs to be further considered. Fourth, due to the limitations of actual environment, this paper collects limited data for the decision-making of fire disaster. It is necessary to enrich the case database, in order to improve the operability of decision-making methods.

\section{Data Availability}

The numerical application data used to support the findings of this study are available from the corresponding author upon request.

\section{Conflicts of Interest}

The authors declare that they have no conflicts of interest.

\section{Acknowledgments}

This work was supported by the National Natural Science Foundation of China (51608363), the Science \& Technology Development Fund of Tianjin Education Commission for Higher Education (2020KJ006), and Training Plan for Young- and Middle-Aged Backbone Teachers of Universities in Tianjin.

\section{References}

[1] H. Sun, Y. Zhang, Y. Wang, L. Li, and Y. Sheng, "A social stakeholder support assessment of low-carbon transport policy based on multi-actor multi-criteria analysis: the case of Tianjin," Transport Policy, vol. 41, pp. 103-116, 2015.

[2] L. Redman, M. Friman, T. Gärling, and T. Hartig, "Quality attributes of public transport that attract car users: a research review," Transport Policy, vol. 25, no. 1, pp. 119-127, 2013.

[3] J. Calimente, "Rail integrated communities in Tokyo," Journal of Transport and Land Use, vol. 5, pp. 19-32, 2012.

[4] D. Sun and S. Guan, "Measuring vulnerability of urban metro network from line operation perspective," Transportation Research Part A: Policy and Practice, vol. 94, pp. 348-359, 2016.

[5] Y. Liu, Z.-P. Fan, and Y. Zhang, "Risk decision analysis in emergency response: a method based on cumulative prospect theory," Computers \& Operations Research, vol. 42, pp. 75-82, 2014.

[6] B. Vincent and S. Carol, "Performance based fire safety regulation under intentional uncertainty," Fire and Materials, vol. 23, pp. 341-347, 1999.

[7] J. Körte, "Risk-based emergency decision support," Reliability Engineering \& System Safety, vol. 82, no. 3, pp. 235-246, 2003.

[8] G. Fu, "A fuzzy optimization method for multicriteria decision making: an application to reservoir flood control operation," Expert Systems with Applications, vol. 34, no. 1, pp. 145-149, 2008.

[9] R. P. Hämäläinen, M. R. K. Lindstedt, and K. Sinkko, "Multiattribute risk analysis in nuclear emergency management," Risk Analysis, vol. 20, no. 4, pp. 455-468, 2000.

[10] J. K. Levy and K. Taji, "Group decision support for hazards planning and emergency management: a group analytic 
network process (GANP) approach," Mathematical and Computer Modelling, vol. 46, no. 7-8, pp. 906-917, 2007.

[11] Z. P. Fan, Y. Liu, and R. J. Shen, "Risk decision analysis method for emergency response based on prospect theory," Systems Engineering-Theory \& Practice, vol. 32, no. 5, pp. 977-984, 2012.

[12] D. Kahneman and A. Tversky, "Prospect theory: an analysis of decision under risk," Econometrica, vol. 47, no. 2, pp. 263-291, 1979.

[13] L. Yu and K. K. Lai, “A distance-based group decision-making methodology for multi-person multi-criteria emergency decision support," Decision Support Systems, vol. 51, no. 2, pp. 307-315, 2011.

[14] J. Geldermann, V. Bertsch, M. Treitz, S. French, K. Papamichail, and R. Hämäläinen, "Multi-criteria decision support and evaluation of strategies for nuclear remediation management," Omega, vol. 37, no. 1, pp. 238-251, 2009.

[15] K.-S. Lim and D.-R. Lee, "The spatial MCDA approach for evaluating flood damage reduction alternatives," KSCE Journal of Civil Engineering, vol. 13, no. 5, pp. 359-369, 2009.

[16] D. Ergu, G. Kou, Y. Shi, and Y. Shi, "Analytic network process in risk assessment and decision analysis," Computers \& Operations Research, vol. 42, no. 2, pp. 58-74, 2014.

[17] K.-C. Shim, D. G. Fontane, and J. W. Labadie, "Spatial decision support system for integrated river basin flood control," Journal of Water Resources Planning and Management, vol. 128, no. 3, pp. 190-201, 2002.

[18] J. K. Levy, "Multiple criteria decision making and decision support systems for flood risk management," Stochastic Environmental Research and Risk Assessment, vol. 19, no. 6, pp. 438-447, 2005.

[19] D. Fogli, C. Greppi, and G. Guida, "Design patterns for emergency management: an exercise in reflective practice," Information \& Management, vol. 54, no. 7, pp. 971-986, 2017.

[20] D. Mendonça, R. Rush, and W. A. Wallace, "Timely knowledge elicitation from geographically separate, mobile experts during emergency response," Safety Science, vol. 35, no. 1-3, pp. 193-208, 2000.

[21] H. Millar, A. Joseph, and A. Mobolurin, "Using formal MS/ OR modeling to support disaster recovery planning," European Journal of Operational Research, vol. 141, no. 3, pp. 679-688, 2002.

[22] C. De Maio, G. Fenza, M. Gaeta, V. Loia, and F. Orciuoli, “A knowledge-based framework for emergency DSS," Knowledge-Based Systems, vol. 24, no. 8, pp. 1372-1379, 2011.

[23] S. Luna and M. J. Pennock, "Social media applications and emergency management: a literature review and research agenda," International Journal of Disaster Risk Reduction, vol. 28, pp. 565-577, 2018.

[24] D. L. Young, A. S. Goodie, D. B. Hall, and E. Wu, "Decision making under time pressure, modeled in a prospect theory framework," Organizational Behavior and Human Decision Processes, vol. 118, no. 2, pp. 179-188, 2012.

[25] K. Goda and H. P. Hong, "Application of cumulative prospect theory: implied seismic design preference," Structural Safety, vol. 30 , no. 6, pp. 506-516, 2008.

[26] M. Lewandowski, "Complementary symmetry in cumulative prospect theory with random reference," Journal of Mathematical Psychology, vol. 82, pp. 52-55, 2018.

[27] M. Klein and M. Deissenroth, "When do households invest in solar photovoltaics? an application of prospect theory," Energy Policy, vol. 109, pp. 270-278, 2017.
[28] B. Vipin and R. K. Amit, "Describing decision bias in the newsvendor problem: a prospect theory model," Omega, vol. 82, pp. 132-141, 2017.

[29] N. Kairies-Schwarz, J. Kokot, M. Vomhof, and J. Weßling, "Health insurance choice and risk preferences under cumulative prospect theory-an experiment," Journal of Economic Behavior \& Organization, vol. 137, pp. 374-397, 2017.

[30] T. Langer and M. Weber, "Prospect theory, mental accounting, and differences in aggregated and segregated evaluation of lottery portfolios," Management Science, vol. 47, no. 5, pp. 716-733, 2001.

[31] H. Bleichrodt, U. Schmidt, and H. Zank, "Additive utility in prospect theory," Management Science, vol. 55, no. 5, pp. 863-873, 2009.

[32] X. Liu, Z. Wang, and S. Zhang, "A new methodology for hesitant fuzzy emergency decision making with unknown weight information," Complexity, vol. 2018, Article ID 5145348, 12 pages, 2018.

[33] I. Basak and T. L. Saaty, "Group decision making using the analytic hierarchy process," Mathematical and Computer Modelling, vol. 17, no. 4-5, pp. 101-109, 1993.

[34] M. Behzadian, S. Khanmohammadi Otaghsara, M. Yazdani, and J. Ignatius, "A state-of the-art survey of TOPSIS applications," Expert Systems with Applications, vol. 39, no. 17, pp. 13051-13069, 2012.

[35] Z. Yue, "A method for group decision-making based on determining weights of decision-makers using TOPSIS," Applied Mathematical Modelling, vol. 35, no. 4, pp. 19261936, 2011. 